\title{
A young patient burdened with many diseases with a very high cardiovascular risk; a therapeutic challenge not only for the doctor
}

\author{
Klaudia Mickiewicz ${ }^{1}$, Mateusz Puchalski ${ }^{1}$, Emilia Sawicka², Anna Lisowska ${ }^{2}$ \\ ${ }^{1}$ Students' Scientific Circle at the Cardiology Clinic, University Clinical Hospital in Bialystok, Białystok, Poland \\ ${ }^{2}$ Cardiology Clinic, University Clinical Hospital in Bialystok, Białystok, Poland
}

\section{Abstract}

A 39-year-old patient with hypertension and a 28-year history of type 1 diabetes with numerous complications in the form of microangiopathy and macroangiopathy was admitted to the Cardiology Clinic due to recurrent angina pectoris accompanied by the intensification of ischemic electrocardiographic (ECG) changes and symptoms of heart failure. In addition, a history of hyperlipidemia, chronic kidney disease, Graves' disease at euthyroid stage.

On admission, the patient hemodynamically stable, arterial pressure $-129 / 75 \mathrm{~mm} \mathrm{Hg}$, regular heart rate, without signs of losses in the pulmonary circulation, visible swelling of the lower limbs and trophic changes on the lower shink. In laboratory tests, mildly impaired renal function (glomerular filtration $56 \mathrm{ml} / \mathrm{min}$ ), high blood glucose values (up to $350 \mathrm{mg} / \mathrm{dL}$ ), glycated hemoglobin $8.7 \%$, hypercholesterolemia. The echocardiographic study showed a worsening of the left ventricular systolic function compared to the previous assessment - a decrease in ejection fraction from 46 to $35 \%$, on ECG - left anterior hemiblock, features of past and anterior wall infarction.

During hospitalization, the therapy of coronary heart disease, hypertension (ramipril, bisoprolol, spironolactone, and furosemide), diabetes (insulin initially used at a variable flow pump, followed by intensive insulin therapy and hyperlipidemia was modified), obtaining satisfactory results in relation to the initial ones. Extended release nitrates were included, and antiplatelet treatment with ticagrelor was continued. Due to elevated cholesterol, the dose of atorvastatin was increased. In case of therapy failure, the PCSK9 inhibitor (evolucumab) and family diagnosis of hypercholesterolemia were considered.

Despite the treatment, angina ailments increased, the ECG performed during the pain revealed ischemic lesions. By decision of the Heart Team, the patient was qualified for accelerated surgery for myocardial revascularization.

Key words: young patient, type 1 diabetes, dyslipidemia, arterial hypertension, comorbidities

Folia Cardiologica 2021; 16, 2: 142-144

\section{Introduction}

Arterial hypertension, diabetes, coronary artery disease and hyperlipidemia, known as diseases of affluence, are a growing problem in medical practice. In the context of diagnosis, treatment and prevention of complications, the occurrence of many overlapping diseases is a particularly difficult challenge which both the doctor and the patient must face. Usually, the lack of a satisfactory therapeutic effect is a consequence of failure to follow recommendations, which, especially when combined with the treatment that does not comply with the latest guidelines and lack of cooperation at the doctor-patient level, can lead to disastrous health consequences even at an early age [1].

Address for correspondence: Klaudia Mickiewicz, Studenckie Koło Naukowe przy Klinice Kardiologii Uniwersyteckiego Szpitala Klinicznego, ul. Marii Skłodowskiej-Curie 24A, 15-276 Białystok, Poland, phone +48 83186 56, e-mail: kl.k.mickiewicz@gmail.com

This article is available in open access under Creative Common Attribution-Non-Commercial-No Derivatives 4.0 International (CC BY-NC-ND 4.0) license, allowing to download articles and share them with others as long as they credit the authors and the publisher, but without permission to change them in any way or use them commercially. 


\section{Case report}

A 39-year-old patient was admitted to the Clinic of Cardiology because of recurrent angina complaints, ischemic changes in electrocardiogram (ECG) and symptoms of heart failure in the form of exercise-induced dyspnea [New York Heart Association (NYHA II)]. Medical history: stable coronary artery disease [Canadian Cardiovascular Society (CCS II)], long-term uncontrolled arterial hypertension, 28-year history of poorly controlled type 1 diabetes treated using the intensive insulin therapy regimen [maximum value of glycated hemoglobin $\left(\mathrm{HbA}_{1 c}\right) 14.8 \%$, blood glucose values up to $350 \mathrm{mg} / \mathrm{dL}$ ), with complications - microangiopathy (diabetic retinopathy - status post-surgery for retinal detachment of the left eye, diabetic nephropathy, diabetic polyneuropathy) and macroangiopathy (2013 - right lower leg amputation due to non-healing neuroischaemic ulcer), past myocardial infarction (three times), numerous percutaneous coronary interventions [2010 - anterior wall myocardial infarction [anterior ST-elevation myocardial infarction (STEMI) treated with percutaneous coronary intervention $(\mathrm{PCl})$ of the left anterior descending together with drug-eluting stent (DES) implantation; October 2016 - re-angioplasty of a left anterior descending, two DES implantation, November 2016 - anterior STEMI due to stent thrombosis, thrombectomy and $\mathrm{PCl}$ of a left anterior descending with implantation of another DES]. In addition, combined hyperlipidemia, chronic kidney disease [stage G3a acc. to Kidney Disease Improving Global Outcomes (KDIGO 2012)], Graves' disease (currently in the stage of euthyreosis; previously treated with thiamazole). The patient was under the care of a diabetology and cardiology clinic. The patient was treated pharmacologically on a regular basis. It should be added that the patient's passive attitude during the treatment process and his negative attitude towards therapeutic decisions raise doubts as to the patient's compliance with recommendations.

On admission to the hospital, the patient was hemodynamically, cardiovascularly and respiratorily stable, fully conscious and verbally responsive. Physical examination: regular cardiac activity, no signs of pulmonary hemostasis, swelling of the lower limbs and trophic lesions of the lower legs. Arterial blood pressure $-129 / 75 \mathrm{~mm} \mathrm{Hg}$, heart rate $-98 / \mathrm{min}$. Laboratory tests: kidney failure [glomerular filtration rate (GFR) $56 \mathrm{~mL} / \mathrm{min}$ ], $\mathrm{HbA}_{1 \mathrm{c}}$ - maximum values in the medical history, i.e. $14.8 \%$, combined hyperlipidemia [total cholesterol $365 \mathrm{md} / \mathrm{dL}$, low-density lipoproteins (LDL) $259 \mathrm{mg} / \mathrm{dL}$, triglycerides (TG) $223 \mathrm{mg} / \mathrm{dL}$. ECG: sinus rhythm $-66 / \mathrm{min}$., left anterior hemiblock (LAH), and signs of the past anterior and inferior wall myocardial infarction. Echocardiography: deterioration of left ventricular systolic function compared to the previous evaluation (April 2017 ) - ejection fraction (EF) decrease from $46 \%$ to $35 \%$.
The therapy of ischemic heart disease, arterial hypertension, hyperlipidemia, and diabetes was modified during hospitalization, obtaining satisfactory results compared to the initial ones. Medications used: ticagrelor $2 \times 90 \mathrm{mg}$, acetylsalicylic acid (ASA) $1 \times 75 \mathrm{mg}$, ramipril $1 \times 5 \mathrm{mg}$, bisoprolol $1 \times 10 \mathrm{mg}$, ivabradine $2 \times 7.5 \mathrm{mg}$, spironolactone $1 \times 25 \mathrm{mg}$, atorvastatin $1 \times 40 \mathrm{mg}$, furosemide $1 \times 1 \mathrm{am}$ poule (administered intravenously). Long-acting nitrates were added, and the antiplatelet therapy with ticagrelor was continued. In the case of the diabetes treatment, insulin in a variable flow pump was initially applied, followed by intensive insulin therapy (insulin glulisine and glargine), gradually achieving satisfactory blood glucose values and a decrease of $\mathrm{HbA}_{1 \mathrm{c}}$ up to $8.7 \%$. Despite the therapy with atorvastatin, high levels of LDL-cholesterol and TG were noted. The dose of statin was increased to $80 \mathrm{mg}$ and ezetimibe was added to the therapy. In case of failure, proprotein convertase subtilisin/kexin 9 (PCSK9) inhibitor (evolocumab) and diagnosis for familial hypercholesterolemia were considered.

In spite of pharmacotherapy, angina complaints were recurring. Echocardiography performed during the chest pain revealed that ischemic lesions above the anterior wall were found to be worse (negative T wave in leads V2-V4). By decision of the patient's cardiologist, the patient had been qualified for an expedited surgical procedure of myocardial revascularization, which was performed in the Cardiac Surgery Department of the University Hospital.

\section{Discussion}

According to the 2019 European Society of Cardiology (ESC) guidelines, a patient suffering from type 1 diabetes (lasting over 20 years) with numerous complications, cardiovascular disease, hypercholesterolemia and arterial hypertension is classified as an extreme high-risk cardiovascular patient despite their young age. In this group, special attention is paid to the necessity of tight blood glucose control; the recommended $\mathrm{HbA}_{1 \mathrm{c}}$ level is $<6.5 \%$ [2], the blood pressure should be reduced to $<130$ and $<80 \mathrm{~mm} \mathrm{Hg}$ for systolic and diastolic arterial blood pressure respectively [3].

In the group of extreme high cardiovascular risk, during secondary prevention, the recommended target value for LDL is to reduce it by $50 \%$ and reach the LDL target value $\leq 55 \mathrm{mg} / \mathrm{dL}$. A special group should be identified (patients who have had a second cardiovascular event associated with atherosclerosis within the last two years while taking the maximum, tolerable dose of statin) - a reduction of $\mathrm{LDL}<40 \mathrm{mg} / \mathrm{dL}$ may be considered among these patients. In the case of a maximum dose of statin with a lack of satisfactory therapeutic effect it is justified to include ezetimibe, followed by PCSK9 inhibitors. 
Furthermore, in such patients, special attention is paid to the appropriateness of prolonged dual antiplatelet therapy to prevent cardiovascular events. It should be remembered that the coexistence of diabetes and vascular diseases of the lower extremities increases the risk of limb amputation by 5 times, and this risk increases with the duration of the disease.

The ESC 2019 guidelines for the diagnosis and treatment of chronic coronary syndromes indicate the benefits of combination therapy (ASA + rivaroxaban) in patients with chronic coronary syndromes, diabetes, and peripheral artery disease (PAD) [4]. In the COMPASS (Cardiovascular Outcomes for People Using Anticoagulation Strategies) trial, the use of such therapy was associated with a reduction in the number of ischemic events compared to ASA monotherapy. Particularly high reduction of cardiovascular risk was observed in patients with diabetes, PAD, moderate chronic kidney disease, i.e. in those like the patient in question [5].

The procedure described above will reduce the prevalence rate of adverse cardiovascular events. The problem is the lack of certainty regarding the continuity of treatment in outpatient conditions, especially that the percentage of patients with chronic diseases that do not comply with medical recommendations is estimated to be as high as $60 \%$ [1]. To achieve therapeutic success, the necessity of applying the model of doctor-patient equivalence, where the level of adherence to medical recommendations is increased by the patient's active participation in the therapeutic process, is increasingly emphasized [6]. The necessity for doctors to follow the recommendations of scientific societies concerning effective treatment of particular disease entities is not without significance either.

\section{Conflict of interest}

The authors declare no conflict of interest.

\section{References}

1. Winnicki M, Basiński K, Szyndler A, et al. Jak poprawić stopień przestrzegania zaleceń terapeutycznych i jakość współpracy lekarz-pacjent? Choroby Serca i Naczyń. 2016; 13(3): 194-202.

2. Araszkiewicz A, Bandurska-Stankiewicz E, Budzyński A, et al. 2019 Guidelines on the management of diabetic patients. A position of Diabetes Poland. Clin Diabetol. 2019; 8(1): 1-95, doi: 10.5603/ /dk.2019.0001.

3. Cosentino F, Grant PJ, Aboyans V, et al. ESC Scientific Document Group. 2019 ESC Guidelines on diabetes, pre-diabetes, and cardiovascular diseases developed in collaboration with the EASD. Eur Heart J. 2020; 41(2): 255-323, doi: 10.1093/eurheartj/ehz486, indexed in Pubmed: 31497854.

4. Knuuti J, Wijns W, Saraste A, et al. ESC Scientific Document Group. 2019 ESC Guidelines for the diagnosis and management of chronic coronary syndromes. Eur Heart J. 2020; 41(3): 407-477, doi: 10.1093/eurheartj/ehz425, indexed in Pubmed: 31504439.

5. Vanassche T, Verhamme P, Anand SS, et al. Risk factors and clinical outcomes in chronic coronary and peripheral artery disease: an analysis of the randomized, double-blind COMPASS trial. Eur J Prev Cardiol. 2020; 27(3): 296-307, doi: 10.1177/2047487319882154, indexed in Pubmed: 31615291.

6. Vahdat S, Hamzehgardeshi L, Hessam S, et al. Patient involvement in health care decision making: a review. Iran Red Crescent Med J. 2014; 16(1): e12454, doi: 10.5812/ircmj.12454, indexed in Pubmed: 24719703. 